Instructions for authors, subscriptions and further details:

http://brac.hipatiapress.com

\title{
La página ideal de Sol LeWitt
}

Eugènia Agustí ${ }^{1}$

1) Universidad de Barcelona. España

Date of publication: June $3^{\text {rd }}, 2014$

Edition period: February 2014-June 2014

To cite this article: Agustí, E. (2014). La página ideal de Sol LeWitt. Barcelona, Research, Art, Creation, 2(2), 221-247. doi: 10.4471/ brac.2014.10

To link this article: http://dx.doi.org/10.4471/brac.2014.10

\section{PLEASE SCROLL DOWN FOR ARTICLE}

The terms and conditions of use are related to the Open Journal System and to Creative Commons Attribution License (CC-BY). 


\title{
The ideal page of Sol LeWitt
}

Eugènia Agustí

University of Barcelona

(Received: 20 December 2013; Accepted: 28 April 2014; Published: 3 June 2014)

\begin{abstract}
"The ideal page" is an essay about Sol Le Witt's Wall Drawing \# 1126 Whirls and Twirls 1 (2004), which can be seen on the ceilings of the lecturer's hall of the Panizzi library in Reggio Emilia, Italy. With this exciting vision on our minds, this essay takes us on a journey through time, although we stay in the same place, in Italy, recovering the palette of the fresco paintings from the early Renaissance, applied in Giotto's and Piero della Francesca's figures, both of them Le Witt was devoted for.

The comparative reading which indeed occurs reversely, starts with murals, tainted in diluted colours, and continues with a revision of the minimal period, under the reference of Le Witt's understanding of the book Mallarmé as a multiple microcosm. From the word to the book, he regards it as a small universe reigned by a universal relationship: movement-space-time. This universe bares the key for Le Witt's interpretation of Mallarmé's stylistic composition, suggesting a regulated structure.
\end{abstract}

Keywords: Sol LeWitt, Mallarmé, colour, language, abstraction

2014 Hipatia Press

ISSN: 2014-8992

DOI: $10.4471 /$ brac. 2014.10

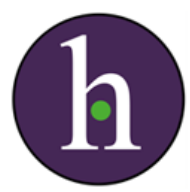




\section{La página ideal de Sol LeWitt}

Eugènia Agustí

Universidad de Barcelona

(Recibido: 20 Diciembre 2013; Aceptado: 28 Abril 2011; Publicado: 3 Junio 2014)

\section{Resumen}

"La página ideal" presenta un ensayo sobre la obra de Sol Lewitt, Wall Drawing \# 1126 Whirls and Twirls 1 (2004), ubicada en el techo de la Sala de Lectura de la Biblioteca Panizzi en Reggio Emilia, Italia. Bajo esta excitante visión que sobrevuela nuestras mentes, el artículo emprende un recorrido, trasladándonos en el tiempo sin movernos de Italia, para recuperar la paleta de los frescos del primer Renacimiento en las figuras de Giotto y Piero della Francesca, por quienes LeWitt manifiesta una gran devoción.

Este símil de lectura que emprenderemos se realiza a la inversa, y desde los murales teñidos con tintas diluidas, pasamos a revisar el período minimal a través de la lectura que LeWitt hace del libro en Mallarmé, entendido como un microcosmos múltiple. Desde la palabra plantea el libro como un pequeño universo regido por la relación universal: movimiento-espacio-tiempo. Este universo le aportará claves en relación a las ideas de una estructura reglamentada que LeWitt interpreta en la composición estilística de Mallarmé.

Palabras clave: Sol LeWitt, Mallarmé, color, lenguaje, abstracción 


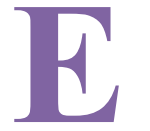

1 dibujo ha sido una práctica constante en Sol LeWitt (1928-2007) desde sus inicios, probablemente porque es al mismo tiempo lo más concreto y lo más abstracto. Es la primera definición gráfica, es donde se sintetizan más esfuerzos, es donde comienza el mínimo absoluto para que exista el universo, tal y como él proclama. Los dibujos se van sucediendo concatenadamente persiguiendo el sentido que marca la mente, devienen gestualidades del pensamiento. Un orden y una metodología conducen este comportamiento hacia un sentido, el sentido artístico.

\section{La página ideal}

Sobre una retícula compuesta por 32 rectángulos que corresponden a tres órdenes de medidas diferentes se ha insertado el centro de la figura ideada por Sol LeWitt. Una docena de grandes curvas perimetrales delimitan esta curiosa y compleja forma que a la vez contiene una cantidad importante de contracurvas interiores, intersecantes a los trazos concéntricos derivados del perímetro externo. Se trata de Wall Drawing \# 1126 Whirls and Twirls 1 (2004). Resulta ser la página ideal para una lectura sobre Sol LeWitt.

El complicadísimo proceso matemático contrasta con el sentido más vital y humorístico que solo los colores seleccionados permiten consentirle. Son seis los colores que LeWitt ha pautado para esta ocasión: rojo, amarillo, azul, naranja, verde y violeta. Colores acrílicos aplicados con rodillo. El resultado es el de una superficie de color completamente plana, con un enorme grado de interactividad. Los matices han desaparecido en el wall drawing que estamos describiendo: las superficies son homogéneas y uniformes, la forma se repliega sobre si misma para ofrecer exclusivamente los colores que la componen. Esta significación alternativa que los colores primarios, secundarios y complementarios le confieren, sustrae cierta trascendentalidad a la obra. Se hace patente un hecho diferencial en relación a como interpretar o intuir en etapas precedentes sus dibujos murales de las décadas de los años ochenta y principios de los noventa.

El techo de la Sala de Lectura de la Biblioteca Panizzi de Reggio Emilia (Italia), ideal para la proyección de esta forma aislada, recibe este único contenedor bidimensional. A diferencia de otras ocasiones no son múltiples elementos sin jerarquía o dispuestos según criterios de seriación los que conforman el dibujo, sino una figura plana exenta de fondo. En esta nueva 
manifestación morfológica estructurada con la máxima rigurosidad, la máxima sensibilidad y la máxima idealización del concepto a los cuáles nos tiene habituados, la influencia entre forma y color es recíproca. Interactúan alternativamente haciendo creíble que el desplazamiento visual pueda realizarse por debajo, por encima y entre las curvas solapadas. Corrobora la capacidad ilusoria del dibujo más allá de las posibilidades perceptivas reales.

Podría ser esta la forma que reivindicaba Donald Judd el año 1976 al decir: "La principal virtud de las formas geométricas es que, a diferencia del resto del arte, no son orgánicas. Una forma que no fuese geométrica ni orgánica sería un descubrimiento importantísimo" (Judd, 1991). La transformación discontinua que apreciamos si vamos siguiendo alguno de los recorridos que marca el dibujo aumenta con la intermitencia de los colores. Como en la cinta de Möbius, este objeto bidimensional ofrece una sola cara y no es orientable.

El grosor de las curvas se mantiene regular, pero no sucede así en la anchura de las casillas que va siendo variable durante todo el laberinto, dificultando el seguimiento visual de esta teselación orgánica. Si unimos la exuberancia cromática a la sensación de aceleración luminosa de esta suerte de meandros, nos sentimos acogidos bajo una especie de caos cosmogónico equivalente a la densidad que presentan ciertos fluidos de diferente viscosidad. En la disposición interna, la concatenación individual de las casillas, aparentemente infinitas y obsesivas nos dirige de una parte a otra; observamos una cadena donde las partes están vinculadas a un todo, no hay ninguna referencia, nada que indique donde empieza ni donde termina. Deducimos que si la seriación significa que todas las partes de la obra reciben el mismo trato siendo consideradas de igual importancia, estaríamos situados ante la recreación de la idea permanente de LeWitt: individualmente cada color fragmentado sería equiparable a un elemento de sus premisas de seriación. La importancia es su valor en el total del conjunto. Con la sucesión interna LeWitt puede superar la repetición de las unidades de color y pasar a una estrategia más prolífica.

Seguidamente, la particularidad destacable es la disposición de la coloración dentro de estas circunvoluciones. Una de las características esenciales del color es su inestabilidad y no todos los colores tienen el mismo grado de mutabilidad. Alteración inevitable asociada al transitar, al fluir, a la dinámica. Sinuosidad que nos transporta a una hiperactividad, programada mediante la diagramación de estos colores que nos conducen a seguir este itinerario de rodeos prefijado por los verdes, rojos, morados, amarillos, azules y naranjas. Asistimos a una actividad cinética de una sorprendente provocación por contraste simultáneo que nos deja estupefactos. Nuestro órgano de la visión 
no demuestra suficiente habilidad para adaptarse y cambiar los aspectos del color por la influencia de los colores fronterizos.

Ante la connotación orgánica de este indefinible circuito de curvas, se activa nuestra facultad evocativa bajo esta nebulosa luminosa y esclarecedora. Nos invita a la admiración, por medio de la que puede ser la acción más contemplativa de todas: mirar el cielo. ¿Qué mejor idea que una lectura del color sobrevolando nuestro pensamiento durante una sesión de estudio? Estímulo de la vitalidad cerebral a través del gesto matemático que conjuga azar y control.

Utilizando recursos de alta complejidad matemática — para hacernos una idea de la envergadura del proyecto, el cálculo matemático de preparación del dibujo mural en el espacio duró alrededor de tres semanas. Dibujarlo costó diez días, mientras que la aplicación del color implicó tres asistentes y nueve ayudantes, durante poco más de un mes - establece un puente de evasión, abre una vía hacia la imaginación. Sintonía entre concepto y arte. Idea y arte. La belleza de las ideas. No es la primera vez que LeWitt utiliza los colores acrílicos Lascaux, aplicados a razón de cuatro o seis manos hasta obtener la solidez requerida. Los colores ya estaban presentes en Continuous Forms (1987); en la serie Curves and Loops donde el valor caótico de las curvas se incrementa con la interactividad de la gama; en el Wall Drawing \#972. Forma isométrica contornos (2011), instalada en el Museo Irlandés de Arte Moderno de Dublin; en Splat (2001), ubicado en el centro de arte CaixaForum de Barcelona; en los Wall Drawings 1045, 1026 y 1047 Barras de color (2002), presentados en la fundación Pedro Barrié de la Maza en La Coruña (España) o en el Wall Drawing \# 1110 (2002) de la Hallmark Cards Inc. en Kansas City (USA).

En anteriores ciclos de su extensa obra, el despliegue mural nos situaba en otras condiciones de percepción, nos persuadía para una completa inmersión en su geometría del color. Ahora, estamos invitados a la contemplación. Los cambios de técnica, la escala, los elementos formales del dibujo mural han ido variando con el paso del tiempo, pero existe una continuidad desde 1968: "quería realizar una obra que fuese lo más bidimensional posible. Me pareció más natural trabajar directamente sobre la superficie de la pared que fabricar una construcción, trabajar en ella, para después colocarla en la pared" (LeWitt, 1970).

Si en el Trecento y el Quattrocento desvelar el misterio de la imaginería a los fieles era la misión, LeWitt escoge un sistema organizativo de similares características, incluso más pregnante y más enigmático, como es la figuración 
geométrica, despojada de su carga simbólica pero con todo el potencial experimental del dibujo proyectual para ensayar todo un ejercicio sobre el color que trasciende la propia geometría: la conciencia de pertenecer a la tradición de los siglos. La insistencia por contrastar otras realidades de color a lo largo de los años supone cerca de más de 1.100 dibujos murales en los que ratifica su filosofía llevándola a la práctica. Como respuesta al hecho que a cada pared le correspondería un dibujo, esta misma podría extenderse, a que a cada pared también le corresponderían unos colores determinados. En plural, porque cada ocasión, cada wall drawing es la demostración de la pluralidad del color. La confirmación, una vez más, que el color siempre "es" en relación a otros, y que somos capaces de nombrarlo, por comparación con su próximo.

Aunque en su propósito inicial buscaba un sistema de trabajo que le permitiese distanciarse tanto de la pintura como de la escultura, el desarrollo de los dibujos murales le lleva paulatinamente a inclinarse por efectos pictóricos, o por los dibujos de color, - como queramos nombrarlo-, bajo otras convenciones que ya ha procurado establecer y documentar. La calidad de estas paredes transpira bajo el color. Transpira el muro, transpira el edificio, transpira la cultura que impregna los lugares de destino. Sea una iglesia desacralizada convertida en un nuevo centro de arte, sea la galería de un museo, sea un encargo para una vivienda particular.

"No me preocupa tanto el efecto efímero de estos dibujos en la pared que desaparecerán bajo la capa del color original del lugar donde han sido emplazados, ni establecer relaciones de solidez ni temporalidad" expone LeWitt (LeWitt citado en Montolío, 1996). En este aspecto difiere del planteamiento de los italianos renacentistas: su pintura tenía que perdurar sobre las inclemencias de los siglos. Los frescos estaban pensados para su permanencia. Técnicas ancestrales de preparación del soporte que debía recibir imprimaciones previas a la acción del maestro artista y las fases sucesivas destinadas a sus colaboradores. El paso de los siglos ha jugado en contra de la conservación y el mantenimiento de estas maravillosas obras que en la envergadura de su proyección, evidencian su afán de permanencia.

En referencia a la estabilidad estaríamos de acuerdo con Montolío (1996) cuando comenta: "Algo nos sugiere que continua perdurando, pero esta sensación no viene dada por una duración material ni por una proyección hacia un futuro sin plazos, sino quizás por elementos como la posibilidad de avanzar infinitamente las series proyectadas o por la misma idea de perfección e inmutabilidad que atribuimos a la geometría. En Paragraphs escribía que su propuesta conceptual implicaba que "la idea se convierte en una máquina que 
produce arte" y "que el arte conceptual busca implicar la mente del espectador más que a su ojo o a sus emociones" (LeWitt, 1996, p. 50).

Queda bien claro que el Wall Drawing \# 1126 Whirls and Twirls 1 de la Sala de Lectura Panizzi no está exento ni de emociones ni de visualidad. A LeWitt le interesa la multiplicidad de las cosas, en especial la multiplicidad de las cosas que pueden generarse a partir de una idea simple. Podríamos aplicar la sentencia que el hábito sustrae a la repetición algo nuevo: la diferencia (Deleuze, 2002, p. 124). En esta dirección, a base de estipular un método serial encontramos una nueva aportación en la obra de LeWitt: el hecho diferencial. Y más aún, podemos añadir a esta diferencia otro aspecto: Sol LeWitt inaugura el concepto de "dibujo mural" distinguiendo su obra de la metodología pictórica. Esta separación sustrae a la pintura la magnitud de la tradición y hace diferencial su trabajo al decantarse por el dibujo.

La lectura sobre el color que podemos extraer de LeWitt es que el arte llega a alterar nuestra percepción modificando nuestra manera de entender las convenciones. LeWitt supera las normas de la pintura y establece que la percepción de ideas conduce a nuevas ideas; la predisposición a comprender de otras maneras el color nos lleva también a imaginar otros resultados para aspectos colorísticos en que dibujo y color no están separados, sino en continuidad. Cubos, prismas, poliedros, pirámides, ondulaciones y bucles, dejan de ordenarse según la idea común de serie, se transforman en los murales siendo parte de la propia obra, con igual importancia, pero ya no surgen de la misma idea básica, y por lo tanto, cada parte individualmente ya no es igual a otra.

\section{Viaje a Italia}

"Me gustaría que mis trabajos llegasen a cuanta más gente, mejor... También me gustaría crear una belleza universal... Me gustaría producir alguna cosa que no me avergonzara enseñar a Giotto”, confesaba Sol LeWitt a MillerKeller. (1994, p.112).

En el primer periodo se podía hablar de confrontación y aislamiento del espectador en relación a las obras. En Whirls and Twirls 1 (2004) la sensación es envolvente, estamos insertándonos en su espacialidad. El sentido de fresco en sus dibujos murales no obstante, obedece más a un análisis de dimensión. Esta ampliación se multiplica y abarca todos los sentidos. Al contemplarlos podemos hablar de sensaciones, emociones, atmosfera, también incluso 
de una reivindicación del color ante el dibujo, de un color como portador de contenidos, de un color que se distancia del carácter artificial de las coloraciones de Frank Stella, Donald Judd o Elsworth Kelly.

Color que, durante un amplio período, toma unas connotaciones naturalistas próximas a los frescos italianos del Trecento y del Quattrocento que tanto admira. "Piero le atrajo por su sentido del orden, al cuál sobreponía un sentido de la pasión y del ritual" dejaba constancia en una entrevista el año 1993 en la revista Art Monthly. Desde el momento en que se siente interesado por Giotto y Piero della Francesca no puede desvincularse de estas filiaciones con la historia del arte europeo. Su obra provoca una serie de replanteamientos entorno a preocupaciones tradicionales que tienen mucho que ver con las búsquedas de la pintura contemporánea. Sus largas estancias en Italia respiran en muchas de sus obras. En realidad no existe diferencia entre el LeWitt de los artículos conceptuales y el de los wall drawings; se trata de la misma actitud estética, la pintura continua siendo una "cosa mental", tal y como lo quería Leonardo da Vinci.

El uso del color en el Renacimiento disfrutó de un deleite que no volveremos a ver hasta el siglo XX, cuando los pintores harán del color el tema de su arte. Para este uso podemos distinguir las diversas interpretaciones que los artistas de ese momento otorgaron a aquel "renacer". Los artistas buscarán nuevas maneras de organizar la gama creciente de colores a su disposición. Por primera vez en la historia, los pigmentos ya no debían ofrecerse a la devoción de una deidad, se intentaba representar el mundo tal y como se ofrecía a los ojos.

Giotto di Bondonde (1267-1337), fundador de la escuela florentina de pintura, asentó los fundamentos innovadores de la futura representación pictórica en su tentativa de dar relieve a los objetos, representándolos de manera tridimensional, mediante luces y sombras creadas por una fuente específica de iluminación. Por primera vez los objetos y las personas representadas proyectaban sombras, superando la rigidez de las formas que caracterizaban el arte bizantino. Curiosamente esta aceptación durante la Edad Media se consideraba irrelevante. La pintura era una manera de narración sin palabras y alcanzando el mensaje se daban por satisfechos. No obstante, dicha categoría narrativa era primordial. Siendo el lugar, la pintura era también la ocasión suntuosa que no existiría si no fuese por su condición de noble o sagrada. El público disfrutaba de la neutralidad de los espacios que la acogían. La naturaleza del muro, en este sentido, atraerá también a LeWitt.

Giotto incorpora al espectador en la escena donde ocurre la acción, 
concentrando todo su interés en este punto, promueve su contemplación; a su vez convierte el tiempo en elemento pictórico, la imagen ya no es un símbolo de lo inmutable, más bien queda fijada en un momento pasajero del tiempo real. Este hecho tuvo repercusiones extraordinarias para los pintores traspasando las fronteras temporales para llegar a principios del siglo XX, cuando los cubistas recuperan su figura y la mirada hacia su pintura. La liberación de la composición medieval dio paso a una diversidad de formas y colores para interpretar. Además, el artista del Renacimiento adquirió la capacidad de colocar los objetos con precisión en el espacio. Estas características del lenguaje de Giotto no se escapan a LeWitt quien de manera casi reverencial nos explica como querría mostrar al artista en calidad de discípulo, su aportación a la creación artística, algo de una belleza que transcienda el tiempo, tal y como ha sucedido con las obras de Giotto.

En La capilla de los Scrovegni ya encontramos una idea de serie con ciertas analogías asociables a la obra de LeWitt. Ampliando ciertos matices de concepto, el punto de donde surge la noción secuencial no distaría demasiado. Las escenas de Giotto están configuradas de tal manera que, como pinturas adquieren un significado propio, y en conjunto transmiten el impulso necesario para la continuidad de la historia. La acción también se impulsa reproduciendo los mismos edificios en diferentes imágenes. La repetición de situaciones espaciales no solo transmite la idea de un flujo narrativo continuo, sino también, de manera especial, el lugar correspondiente a la acción. La clara definición del lugar hace que lo que sucede parezca muy natural. Mediante esta localización la acción obtiene una presencia directamente inteligible. Presencia que se mantiene con los personajes, sus encuentros y la expresión de sus sentimientos reproducidos de manera muy diversa.

El artista todavía no pinta los paisajes alejados ni los espacios interiores profundos que tan representativos serán del Renacimiento posterior. Aún así, sus edificaciones, templos y montañas no son simples alusiones. Son elementos que dan ritmo a la acción y el color es parte activa de esta rítmica que acompaña a la acción. De algún modo LeWitt recoge estas sensaciones elementales y primitivas que transmitirá a sus volúmenes estáticos: a medida que los representa reiteradamente, aún desarrollándolos con más complejidad, nos suministra las claves para identificarlos y comprenderlos. Gracias a las axonometrías y otros recursos de la perspectiva transforma sus objetos tridimensionales, que en sucesión — como en la narrativa de Giotto-, irán abriéndose bidimensionalmente en el espacio, desplegando el cúmulo de ideas contenidas destinadas a un inevitable placer sensorial. 
Si tal como hemos apuntado anteriormente, afirmaba que su valoración sobre la "idea conceptual" implica a la mente del espectador más que a su percepción o emociones, se podría relativizar su afirmación y constatar que es precisamente desde la emoción que nos transmite la visión de sus murales que estamos calificados para captar "su idea": qué les da vida, qué indagamos en su intervención mental. Discutir sobre el orden mental es una falacia, las interpretaciones son individuales más allá de lo que dicta el propio artista. La redución a la lógica o a resultados estrictamente formales no es explicable en un artista como Sol LeWitt que oculta connotaciones de envergadura más hedonista, que no solo reduce la experiencia de la contemplación del objeto artístico a una comprensión intelectual, a pesar de afirmar que una de las razones para que su obra sea geométrica tiene origen en el deseo de hacerla sencilla y simple.

El tratamiento del color es decisivo en su sistematización, como lo es también en la activación del sentido espacial de sus series. Ya bien sea en un despliegue extensible en la pared o en una sucesión de imágenes catalogada, qua vamos viendo hoja por hoja, de manera más próxima a la carta de color a través de impresiones sobre papel como la Serie de 100 cubos, originales en gouache que se muestran expuestos en una pared donde los cinco colores presentes en cada obra (los tres destinados a las tres caras visibles del cubo, más el color del perfil que los encuadra) interactúan entre ellos como las tinturas de la gama del Atlas de Chevreul, o compilados en un libro de artista de edición limitada de una excelencia cromática sin paragón. Las sensaciones son homónimas, las percepciones nada distantes.

El color en Giotto, bajo la influencia de Cimabue y los mosaicos florentinos, destaca por ser singularmente luminoso, basado en el inventario de las técnicas del "buon fresco" y el "secco fresco": blanco de cal, azurita, ocre amarillo, ocre rojo, tierra verde vienen a nuestros ojos como los azulados turquesas, verdes semi-claros, azules oscuros, delicados matices grises-azulados plateados, débiles tonalidades violáceas y rosadas, rosas amarillentos intensos... Observando de cerca la serie citada de LeWitt, y salvando las distancias técnicas del gouache, las coloraciones aplicadas beben de las que acabamos de citar. La posibilidad de observar estas obras en directo, y algunos de sus wall drawings ratifican esta debilidad por el color desde el conceptualismo.

Las pirámides desplegadas por Sol LeWitt toman una identidad diferente, pasan a ser una nueva forma independiente que ya no está vinculada al sistema serial. La complejidad de estas nuevas figuras es de una bellísima policromía. A partir de los colores directos usados en la impresión del papel y sus evoluciones 
en tintas aguadas, las coincidencias con la paleta italiana se hacen visibles, y admirándolas, podemos hablar de preciosismo. Los efectos de lavado dejan respirar los variados colores que se aplican en una misma área del muro; inicialmente se empieza con el color directo con bases de tintas aguadas que se van embelleciendo por las sucesivas aplicaciones de otras tintas. La mezcla del color se produce directamente sobre el muro y no durante una preparación previa. Se utiliza un sistema elaborado de aplicación con trapos de algodón en diversas fases, hasta que el color va subiendo consiguiéndose el tono programado, que recuerda al entintado con tarlatana de la lámina de metal en calcografía. La obra evoluciona paralela a la movilidad que nos muestran las últimas sucesiones de estructuras concatenadas que se van abriendo al ocupar la pared, asimismo las sucesivas incorporaciones de otros recursos dibujísticos conducen la evolución de su obra hacia la expresividad y la subjetividad.

LeWitt explica como se siente también seducido por el sentido del orden que se respira en la obra de Piero, por sus figuras poderosas y sublimes, enigmáticas y a la vez emblemas de su época. Entre sus muchas reflexiones sobre el arte, Piero della Francesca (1420-1492) dejó escrito que las formas son "hermanos en buena armonía en el salón ancestral del espacio" (della Francesca citado en Laskowski, 2000), y se hace patente que el artista del Renacimiento se servía de la composición geométrica para acentuar sus propósitos. Podemos ver que la construcción de sus obras se basa en formas geométricas puras y la composición se desarrolla a partir de cuerpos idealizados, tema sobre el que Piero escribió su tratado De corporibus regularibus. ¿Podría estar LeWitt haciendo un guiño a las nubes de Piero, con su "forma nube" del techo de la Biblioteca Panizzi?

Las nubes que aparecen en repetidas ocasiones en su obra, recuerdan por su forma la rotación de los cuerpos geométricos. Sol LeWitt utiliza recursos sencillos para insinuar movimientos similares. Los colores de Piero llevan a término exactamente la misma función de definición del espacio que sus formas. Constituyen un ejemplo de las diferentes tonalidades de un color, degradadas rítmicamente, estimulan al observador para fijarse en la distribución espacial. Esta característica se convirtió con el tiempo, en una de las peculiaridades estilísticas remarcables de Piero della Francesca. Resalta por una combinación singularmente armónica del compendio renacentista, donde el ocre, el púrpura azulado, el rojo, el rosa, el tierra verde y "verdigris", y el azul de ultramar son algunos de los tonos utilizados en la mixtura de sus armonías.

$\mathrm{Su}$ inventario formal y colorístico constituye uno de los momentos 
culminantes en la pintura del primer Renacimiento, por sus personajes bellísimos e imponentes, por su colorido y serenidad espiritual, sus creaciones continúan sorprendiendo por su modernidad. Consiguió conciliar los conocimientos científicos y artísticos de su época con la visión espiritual del mundo, ejerciendo de mediador entre el Gótico y el Renacimiento, entre la tradición y la modernidad.

Piero crea una rítmica contrastada de colores cálidos y fríos a través de las vestimentas de los dignatarios eclesiásticos. Asigna unas tonalidades frías o cálidas en función del estatus que los personajes representan en la escena de la pintura, por ejemplo, entre la corte eclesiástica y los ángeles; entre los cortesanos y los soldados. También traslada estas relaciones a las fisonomías de los personajes, que vemos aprovecha en diferentes ocasiones, siendo equiparables en su uso al manejo que hace de la geometría. Si nos centramos en la pintura El bautismo de Cristo (1440-60), podemos percibir que las formas básicas de la composición son un cuadrado que sobresale de un semicírculo, cuatro triángulos equiláteros y un pentágono. Los cuatro triángulos convergen en la figura de Jesús, las manos que ocupan el centro del triángulo superior, zona donde se centra la atención de nuestra mirada.

Muchas de sus obras no han llegado a nuestros días; solamente aquellas que han resistido el paso de los siglos. En el caso de los frescos, si traspasamos estos efectos al estado de conservación, la suavidad del color posiblemente sea una causa, aunque ciertos especialistas hablan de la investigación de Piero por desarrollar un colorido intentando recoger con el mayor realismo posible, la atmósfera de las escenas ambientadas al aire libre.

En su obra teórica Sobre la perspectiva en pintura, Piero divide la pintura en tres campos: disegno, commensuratio y colorare (dibujo, proporciones y color). El primer libro analiza la proyección de superficies, el segundo la de los cuerpos geométricos, y el tercero la de los cuerpos complejos y los espacios. En este escrito el artista demuestra porque estaba interesado en la matemática. Ya que domina los conocimientos de perspectiva se puede permitir tomarse pequeñas licencias deliberadas en forma de errores, concebidos a propósito, para que no puedan ser detectadas a primera vista. De esta forma incita al espectador a hacer una lectura de su obra en profundidad y lo mantiene, al mismo tiempo, a una cierta distancia del discurso narrativo. La contemplación de sus pinturas origina un instante de desconcierto que incrementa la humildad y la atención espiritual. Simultáneamente podemos encontrar zonas inconclusas en obras de LeWitt que originan así una nueva figura. Queda a cargo del espectador completar o interpretar a su criterio la 
forma, similar a lo que advertimos en la serie Incomplete Open Cubes (19741982). Este momento desconcertante que buscaba Piero, en LeWitt produce una incomprensión enigmática.

En los frescos de la Iglesia de San Francesco de Arezzo, las diferentes escenas representan la dilatada historia de la Santa Cruz. Los episodios se basan el los textos de la Leyenda Áurea, recopilados por Jacopo de la Voragine entre 1224 y 1250 . Piero no ordena las escenas cronológicamente a diferencia de Giotto, sino que las agrupa de acuerdo a detalles formales que le permiten relacionarlas entre ellas. La ordenación no se presenta secuencialmente a medida que van sucediéndose los hechos, sino de manera simétrica, y la simetría se capta inmediatamente al entrar en la capilla. Este arreglo también lo encontramos en muchas disposiciones de los wall drawings de LeWitt cuando plantea un eje de simetría imaginario a partir del cuál sitúa los murales, generalmente confrontados, como en un efecto espejo. En Arezzo, los frescos están iluminados por la luz natural que proviene de la ventana central de la capilla, convirtiéndolos en un todo unitario. Las figuras siempre aparecen en una distancia similar y tienen proporciones también similares.

Esta composición permite, en concreto, contemplar las escenas de La Adoración de la Santa madera y Encuentro de Salomón con la Reina de Saba donde, si nos concentramos en el vestuario de las cortesanas de diferentes tonalidades (rojizos, rosados, verdes turquesa) asociamos, - una vez superada la distancia de los siglos - la coloración utilizada por el artista americano. Los colores cálidos se alternan en la obra de Piero con otros más fríos, en una gradación sumamente armoniosa. LeWitt se impregna y memoriza la paleta italiana que gradualmente irá depositando de nuevo sobre otras paredes contemporáneas. Coloraciones suaves y moderadas de amarillentos tenues, amarillos rosados, rosas pálidos, rojos mercurio, verdes semiclaros, turquesas muy claros, verdes ultramar, azulverdosos muy profundos, morados que irá aplicando y pasarán de ser paleta a ser carta de color, siguiendo un sistema de tratamiento del color mediante dilución de tintas acuosas que caracterizan su método antes de dar el salto hacia colores más sólidos.

LeWitt realiza un acto de concreción al ser capaz de destilar los conocimientos de estas dos figuras del Renacimiento y lo que supuso su visión, como "renacer" del concepto de arte y cambio sobre sus percepciones. Interpreta el pasado con las claves del pasado. Como constata en sus Sentencias sobre arte conceptual existe la mala costumbre de entender el arte antiguo desde las convenciones del presente y ello nos induce a errores de comprensión. 


\section{Mallarmé y el libro}

La pared se entiende como un espacio absoluto, lo mismo que las páginas de un libro. Uno es público y el otro es privado. Líneas, puntos, figuras, etc., se ubican en este espacio mediante el uso de las palabras. Las palabras son las vías que llevan a entender la ubicación de los puntos. Los puntos se verifican mediante las palabras. (LeWitt, 1996, p. 26).

Sol LeWitt establece un sistema lingüístico, un lenguaje artístico donde las palabras dan a entender la ubicación de los puntos y los puntos se confirman a través de las palabras. En el caso que expone, hemos de considerar los puntos como unidades lingüísticas no como unidades gráficas. En esta afirmación es la palabra la que marcaría el inicio. Mediante la palabra, el artista transcribe las órdenes a sus ayudantes. El mensaje artístico está contenido en unas instrucciones escritas. LeWitt piensa e indica lo que habrá que hacer: el artista concibe y planea el dibujo mural que realizarán los dibujantes. Concebir, planificar y dibujar son acciones ordenadas en la metodología del artista. Cada una de estas transiciones comporta diferentes posibilidades que son organizadas sistemáticamente.

El artista comenta también las aportaciones que en este sentido le ha reportado el estudio de la obra fotográfica de Eadweard Muybridge. Sus instantáneas descriptivas del movimiento humano y animal en sucesión rápida, le sugieren una posibilidad de hacer arte que no depende del momento, sino de una manera de proceder premeditada, consolidada, que da resultados interesantes y apasionantes. De igual modo que la narración de un hombre o un animal corriendo, también las combinaciones de una obra seriada actúan como una narración. Tanto Mallarmé desde la faceta de la escritura como Muybridge, desde la referencia visual, han contribuido a que LeWitt desarrolle una obra derivada de unas premisas elementales, una obra centrada en la noción de serie, como exploración de un orden de posibilidades en una secuencia lógica.

La recopilación de las ideas de Mallarmé sobre el libro y la palabra, acaece un puntal referencial para Sol LeWitt quien demuestra interesarse por la idea de seriación del poeta. LeWitt entiende las paredes como el espacio absoluto de las páginas del libro. Sus contribuciones en el ámbito del dibujo, del grabado y del libro de artista se acercan al microcosmos múltiple de Mallarmé, al 
plantearse el libro como un pequeño mundo regido por la relación universal: movimiento-espacio-tiempo. "El libro, expansión total de la letra, ha de extraer de ella, directamente, una movilidad; y espacioso, por correspondencias, instituir un juego, no se sabe cuál, que confirme la ficción" (Mallarmé, 2002, p. 90). El poeta dividía el libro en micro y macroestructuras, y la secuencia de actuación podía ser regulada por permutaciones dadas, dentro de las cuáles había unas áreas de libre elección. El espectador o lector está en posesión de las claves de la obra, por decirlo de alguna manera; aplicando las reglas del juego, simultánea o sucesivamente, abre la obra y construye una de sus posibles configuraciones.

Dar a la lectura la misma categoría que a la composición quería decir aceptar sus limitaciones naturales en la planificación compositiva: la pared dada por los dibujos murales, por ejemplo en Sol LeWitt. Si éste valora las irregularidades del soporte, imprevistas y azarosas consecuencias sobre el resultado final como parte integrante de la obra definitiva, Mallarmé cita un pensamiento similar en su relación con el impresor cuando encarga la maquetación de un poema:

Desearía unos caracteres bastante apretados, que se adaptasen a la condensación del verso, pero también aire entre los versos, espacio, a fin que destaquen bien unos de otros, lo que es necesario incluso con la condensación. He numerado los poemas. ¿Es útil? En cualquier caso, querría, también, un gran blanco después de cada uno, un descanso, ya que no han sido compuestos para sucederse así, y aunque, gracias al orden que ocupan, los primeros sirven de iniciadores a los últimos, desearía que no se leyese de una tirada y como buscando una ilación de estados del alma que resultasen unos de los otros, cosa que si no es así, dañará el placer particular de cada uno. (Mallarmé, 2002, p. 91).

Registros que pertenecen al mundo de la composición de textos que son imprescindibles en opinión de Mallarmé. Su obra no solo está formada por el sentido de las palabras sino también del efecto visual que estas palabras tendrán en la impresión definitiva. El carácter de la obra de Mallarmé también considera esta sintonía expresiva que en otro caso sería considerada como "detalles" delegables.

Este método de trabajo comienza a advertirse en LeWitt en Variaciones de cubos incompletos (1974). La serie se compone de 122 pequeñas estructuras incompletas de color blanco que desde una plataforma demasiado grande para 
ser captada de una sola mirada, nos sumergen en una experiencia obsesiva que nos obliga a ir eligiendo entre las figuras para detectar cuáles son las especificidades que las diferencian dentro de la serie. En opinión de Krauss se insertan en una retícula sin sentido que refleja una absurda obstinación. La experiencia de estas obras va exactamente en contra de lo que ella nombra "apariencia del pensamiento", sobre todo si entendemos el pensamiento como expresión clásica de la lógica.

Tal expresión, ya sea diagramática o sea simbólica, se basa precisamente en la capacidad de abreviar, de condensar, de tener capacidad para sugerir una expansión con dos o tres términos, de abarcar amplios espacios asimétricos con unas cuantas elipses, de utilizar en resumen la noción de etcétera. La charla de la expansión serial de LeWitt no tiene nada que ver con la economía del lenguaje matemático. (Krauss, 1996, p. 267).

H. R. Zeller sugiere que Mallarmé puede haber sido una de las fuentes más importantes para el posterior desarrollo del arte en dos y tres dimensiones de Sol LeWitt:

Conceptualmente proyectado y orgánicamente integrado que, en lugar de tomar como modelo ideas tradicionales de la forma escultórica o pictórica, emana las ideas de una estructura reglamentada antes de ser pintura, escultura o dibujo. Esta manera de abordar el objeto de arte tiene algunas correspondencias con el constructivismo, pero es más radical porque generaliza totalmente los elementos visuales implicados y no los usa sino después de contar con una estructura reglamentada antes de empezar. (Zeller, 1996).

Sin embargo, el proceso y la generación de las formas adquieren valor metalingüístico. Si consideramos la condensación de la palabra, de la idea y de la forma tienen mucho que ver con la proposición que el artista lleva a la visualización. En la lectura de Mallarmé se intuye el vacío sobre el papel como una posible obra de arte, idea sobre la cual el poeta no llega a ser consciente, pero en cambio LeWitt es capaz de percibir. Como señala Richard Wollheim (1996), Mallarmé describe una situación de pánico al iniciar el procedimiento de su tarea creativa. Su terror, el sentido de esterilidad que experimenta al sentarse ante su escritorio, al enfrentarse ante una hoja de papel en blanco donde se supone que ha de componer su poema y ninguna palabra acude a 
su mente. Podríamos preguntarnos parafraseando a Wollheim: ¿por qué Mallarmé, después de un lapso de tiempo, no se levantaba y presentaba la hoja en blanco como si fuese el poema que hubiese deseado escribir?

Realmente, nada resultaría más expresivo sobre los sentimientos de impotencia y devastación interior del poeta que el papel virgen. Para nosotros, el interés del citado gesto está, naturalmente, en que nos daría un ejemplo extremo del arte minimal o de un grado cero de la escritura. Ahora bien, existen muchas razones para no aceptar el vacío del papel como una obra de arte. El mismo LeWitt, como artista puente de la conceptualización minimalista, se sentiría identificado con la situación descrita. En el caso de sus primeros dibujos tal y como refleja en sus observaciones, se contempla un deseo de integración con el soporte, en el caso del muro, que le llevaría a suprimir cualquier intermediación y escoje dibujar directamente sobre éste para mantenerse más cercano a la bidimensionalidad el espacio circundante. ¿Cuántas veces se habrá encontrado LeWitt en una situación similar? El muro es el espacio de transferencia de la idea de página o lámina, es su particular tour de force con el ideal verificándolo desde la escala humana.

Retomando la sugerencia de Zeller, LeWitt no empieza antes de contar con una estructura reglamentada, refiriéndose también a una disposición mental ideada. Intentar establecer un paralelismo situacional o relacional entre la asociación del vacío del color blanco y la plenitud de contenido atribuible a otros colores, ratifica un binomio de ideas extremas situadas en relación. Nos aproximaría más, si cabe, a la evolución que llevamos observando en su obra, es decir, de las pequeñas estructuras tridimensionales seriadas, meticulosamente pintadas de blanco, a los dibujos murales como Whirls \& Twirls 1, la distancia nos aporta información sobre nuevos contenidos. El arco que trazan estas obras en el tiempo son los registros de su particular conquista del espacio.

La presentación de la hoja de papel en blanco de Mallarmé como si fuese el poema que hubiese querido escribir, podría tener su equivalencia en el campo del arte; no tanto en la producción de una tela en blanco, sino en algo más parecido a querer mostrar el contenido de un estudio vacío: "El espacio abierto, la página en blanco que atraerá tanto la decisión a favor del silencio como la necesidad de la escritura" (Mallarmé, 2002, p.19). Como apunta Mel Bochner (1996), las partes internas de un trabajo en sucesión ininterrumpida son una serie; la siguiente apreciación de Mallarmé ilustraría un poco más la suya propia: 
El poema se imprime, en este momento, tal como lo he concebido: en cuanto a la paginación es donde está todo el efecto. Una determinada palabra, en caracteres gruesos, para ella toda sola, pide toda una página en blanco y creo estar seguro del efecto... La constelación no afectará allá con leyes exactas, y tanto como se permite en un texto impreso, fatalmente un álbum de constelación. El barco escora, de lo alto de una página al bajo de otra, etc.; y aquí reside todo punto de vista (que tuve que omitir periódicamente), el ritmo de una frase en consonancia con un acto e incluso un objeto no tiene sentido si no los imita, y figurando sobre el papel, recogido de la estampa original por la letra sabe reproducir, a pesar de todo, alguna cosa. (Mallarmé, 2002, p. 91).

Este párrafo deviene la argumentación del destino en tanto que ubicación ideal de un poema, a la vez que se convierte en una figuración posible.

Las Sentencias sobre arte conceptual ya incluyen el procedimiento de la serie en la exposición de sus 35 pensamientos numerados intencionadamente, uno tras otro. Esta declaración constata en la asertación final que no se trata de arte, que solo son comentarios sobre arte y solo tienen sentido de esta manera. Cuando LeWitt expone "los juicios racionales repiten juicios racionales" entronca con Roman Jakobson. El método del encadenamiento viene dado por el desarrollo de la idea en que es más importante el "tiempo de enunciación" que el "tiempo enunciado". De aquí que las obras requieran una percepción lenta, una transcurso paralelo al que el autor sigue en su trabajo. Podríamos especular si no existe en LeWitt una doble intención y que el tiempo haga de estas propuestas un texto artístico, y a la manera de Mallarmé las palabras ejerzan los poderes mágicos del lenguaje. La conceptualización de ideas quiere ser una explicación en palabras sobre el pensamiento como universal. La crítica americana Suzy Gablik propone asimismo en su ensayo Progress in Art, que el arte abstracto se presenta como el fruto necesario de algún tipo de crecimiento intelectual universal (Gablik citada en Krauss, 1996, p. 262).

\section{El lenguaje abstracto: entre el enunciado y la síntesis}

La posición artística de LeWitt en la abstracción como medio y representación del lenguaje de su arte no se aleja del argumento que la convierte en un recurso favorable para organizar la diversidad de objetos expuestos a la percepción, la imaginación y al pensamiento. Tampoco de la consideración meditada en 
relación a los elementos metódicamente tratados desde el Trecento por Giotto y el Quattrocento por Piero en sus frescos; en el traslado de la secuencia poética hacia una ruptura o asunción de brecha en el hábito poético de Mallarmé; y en el poso o reinterpretación que de ellos recoge LeWitt en consonancia a sus intereses. Por lo que se hace patente que este recorrido sirve para testimoniar una dialéctica que pone de relieve que les une una sintaxis. En estos tres momentos están definiendo reglas para secuenciar su específica gramática, la de un lenguaje abstracto que más allá de expresar oraciones, piensa o imagina, coordina y ratifica conceptos.

Si la palabra inventa lo que nombra, Mallarmé quiso crear una palabra que reinventara o figurara lo nombrado. Así, si en una primera acepción "abstracción", en el sentido del término griego "aphairesis" designa el proceso mental tanto como el resultado; el hecho de aislar la atención del sujeto sobre aquello particular, no esencial, para centrarla en aquello general inevitable, esencial o primario. Un segundo concepto de abstracción se refleja en el término latín "abstrahere" que significa desvelar, retirar el recubrimiento y extraer una parte de este para un examen más profundo. En otras palabras, seleccionar un elemento o un componente de un dato aislándolo del resto.

En el contexto de la creación artística del siglo XIX se vincula la concepción original de la abstracción a una concentración de lo esencial. La psicología de la Gestalt explica la abstracción entre 1920 y 1930 como un proceso mental de repetición, observación y razonamiento que conduce del todo a las partes y de éstas al todo, a través de las relaciones internas, siendo un proceso fundamental de la actividad creativa. "Abstracción" era un término de taller de uso frecuente en Francia en 1880. Sucesivamente con el fauvismo y después el cubismo, el modelo de obra de arte a la que se podrá calificar de abstracta, empieza a imaginarse. En Alemania se dará una situación diferente. No será en los discursos de los críticos cuando se hablará de abstracción y de abstracto, pero sí a partir de su rica tradición estética, de la psicología experimental y del interés por la ornamentación (teorías de Worringer), como en el caso de Kandinsky. Worringer es el primero en captar las posibilidades de la abstracción como concepto estético, y el primero capaz de entrever un contenido posible en la forma abstracta. La aventura abstracta de las vanguardias descubre una pluralidad de intereses que se manifiesta desde la preocupación lingüística, — común a poetas y artistas-, que se explicitará en una constelación de autores que profundizarán en la creación de nuevos códigos, y en su traducción o traslación a modelos tanto formales como estéticos, en una voluntad de trascendencia de lo real. Algunas de la raíces de 
la abstracción se encuentran en una serie de cambios que se producen a finales del XIX. Para saber cómo funcionan los sistemas de gramática en la abstracción es preciso entender otros hechos acaecidos en el ámbito de la pintura, en el nombrado período del arte moderno. Línea y color seguían sometidos a los intereses de las artes decorativas a finales de siglo. El modelo del lenguaje poético y la música permitieron intuir formas de abstracción cuando ésta todavía no existía. En 1880 los simbolistas se lanzan a lo desconocido, casi iniciando la abstracción. ¿Cómo se produce el camino hacia la abstracción? ¿Cómo se pudieron imaginar, proyectar y después realizar "formas abstractas" cuando todavía no existían? Esta pregunta que siempre se manifiesta cuando indagamos en los inicios del arte, en qué momento, en qué situación, hace que no dejemos de observar los factores implicados con cierta estupefacción.

Es evidente que como en todo proceso de transformación, los cambios van alterando las circunstancias progresivamente y los mecanismos evolutivos necesitan su sedimentación. Parece que hubiesen sido necesarios patrones en los cuáles apoyarse para concebir una cosa radicalmente diferente de aquello que se había realizado hasta el momento. La música fue uno de estos modelos, y ligada a ella, el lenguaje. Pero sobre todo fue el lenguaje poético el que sirvió de pauta. La fascinación por el deslizamiento y desplazamiento de la función denotativa de las palabras hacia su fuerza expresiva y emocional intrínseca hacían de la poesía un lenguaje puro, y los primeros visionarios de la abstracción construyeron un arte "puro" en la acentuación de los medios pictóricos a través de líneas y colores. Una aventura que persigue una gramática de la creación nueva y distinta, y que dará lugar a poéticas tan diferentes como afines en su discurso como las de Kandinsky, Mondrian o Malevich entre otros. Las inquietudes por el lenguaje no eran ajenas al contexto, así Saussure plantea que "el signo lingüístico une no una cosa y un nombre, sino un concepto y una imagen acústica" es decir, respectivamente un significado y un significante. Las ideas de Saussure y Jakobson también traslucen en el pensamiento de Kandinsky, pero es imposible que hubiese leído a Saussure ya que el Curso de lingüistica no fue publicado hasta 1916, y no coincidieron con Jakobson en Moscú hasta el 1919. Estas asociaciones no hacen sino confirmar que ideas parecidas palpitaban en el ambiente.

Una de las fuentes del futurista Marinetti fue René Ghil, como también lo fueron Mayakovsky, Klébnikov y Kruchenik. Ghil escribió el Tratado del verbo (1886) y consideraba a Mallarmé su maestro antes de distanciarse de su ideario. De igual manera existía una consideración recíproca por parte de Mallarmé. Este último pone en evidencia la transformación que provoca el 
lenguaje poético en relación al objeto o al referente. Ghil especifica que en la función ordinaria del lenguaje representativo, la palabra, remite al objeto que se nombra. Jakobson sintetiza en una formula incisiva el lenguaje florido de Mallarmé: "Ninguna palabra poética tiene objeto. Es lo que pensaba el poeta francés cuando decía que la flor poética es la ausencia de todos los ramos". Jakobson emitía esta observacón en su primer texto del año 1919, en un artículo sobre el poeta Khlébnikov, uno de los principales protagonistas del futurismo ruso.

Para entender y ser capaz de hablar del lenguaje del color desde la teoría, el estudio de Chevreul revela hasta qué punto su contribución con De la loi du contraste simultané ha sido útil a abanderados del arte abstracto como Robert y Sonia Delaunay, Mihail Matiouchine, Georges Seurat, Johannes Itten y Josef Albers. Dicho estudio contiene las bases de la estructura de las relaciones puras de los colores y será reinterpretado en sucesivos momentos posteriores.

Después de 1945, sea en París o en Nueva York, la situación del arte se revela completamente diferente. Se acentúa un cambio perceptible en los años 30 cuando la importancia del arte abstracto va declaradamente en aumento. La abstracción geométrica es una corriente que crece, a pesar de los reproches que recibe por el dogmatismo de su posición y el riesgo de academicismo que implica. Las nuevas concepciones responderán a objetivos variados: proponer otras alternativas a la geometría en términos de definición, las referencias a la naturaleza, y la cuestión de la figuración están en el centro de los debates. Las determinaciones de los principales artistas han contribuido a establecer los diferentes sentidos que pueden darse al hecho de la abstracción. En mi opinión es un hecho artístico, un posicionamiento. ¿Qué entendían los precursores por arte abstracto? Quizás compartían la certeza que el arte abstracto es una alusión a la ausencia de representación. En la actualidad numerosos estudios confirman la diversidad de la naturaleza del arte abstracto, y la complejidad de esta observación son los múltiples aspectos que la abstracción toma en la obra de los artistas.

Desde las vanguardias, una de las principales cuestiones entorno a la cuál se articulará el discurso artístico será el análisis de la abstracción como una forma de lenguaje. Entre sus pretensiones estaba abandonar la figuración desvalorizando la formalización anterior, con la opción de crear otra realidad basada en el uso de las formas. La filosofía del lenguaje del formalismo ruso nutrió considerablemente toda la primera abstracción. En definitiva, desde la experiencia de las vanguardias se crea un espacio nuevo de investigación en 
función de los cambios que se están operando en la sociedad. La herencia de los formalistas rusos propicia un desarrollo en la abstracción muy asociado a los valores formales y estrechamente vinculado a los lingüísticos. Una voluntad investigadora orientada a cambiar las narrativas del arte precedente, es la conexión entre la vanguardia y la contemporaneidad que ha dado lugar a una longeva diseminación de producciones y variantes en el arte abstracto. En ese sentido, el siguiente fragmento de Ensayos de lingüistica general de Jakobson puede ser útil para ilustrarlo:

Puede ser que el impulso más fuerte hacia un cambio en la manera de aproximar el lenguaje y la lingüística fuese durante — para mí, al menos - el turbulento movimiento artístico de principios del siglo XX [...]. La capacidad extraordinaria de estos inventores (Picasso, Joyce, Braque, Stravinsky, Klébnikov, Le Corbusier) por rebasar sin tregua sus antiguos hábitos superados, como también su don sin precedentes por conseguir remodelar la tradición más antigua o cualquier otro modelo extranjero sin sacrificar su propia individualidad en la estupefaciente polifonía de creaciones siempre nuevas, estaban íntimamente ligadas a su sensibilidad única para conseguir la tensión dialéctica que existe entre las partes y el todo unificando, entre las partes conjugadas, sobre todo entre dos aspectos de todo signo artístico, el significado y el significante. (Jakobson, 1973).

Del mismo modo que en los primeros inicios hemos visto como se atribuyeron al lenguaje musical y al poético, estímulos detonantes del movimiento abstracto, consecutivamente éste adoptará usos de la lingüística y la semiótica visual a fin de poner en evidencia la naturaleza de los signos comunes al lenguaje y al arte. Cabe subrayar que desde 1945 los defensores de la abstracción hablan de "signos", parece ser la expresión más cualificada para referirlos. Signos de las emociones que experimenta el artista, signos que en el caso de Sol LeWitt se resolverían en una suerte de escritura espacial y que desde su pluralidad reemplazan y sustituyen la realidad ausente, signos del lenguaje personal de cada autor.

En los casos presentados se materializa en la realidad que nos transmiten los frescos del primer renacimiento italiano, coincide con los silencios de Mallarmé y toma nuevamente forma en el lenguaje conceptual de LeWitt. En cierto modo estos tres ciclos resultan integrarse en una estructura léxica intransferible a terceros, pero permutable entre ellos y el lenguaje abstracto. 
¿Por qué? Por la afinidad de su escritura espacial modelada por una dialéctica instaurada en la geometría, como medio de inscripción espacial. Por la voluntad de significar desde un código objetivo basado en el estudio, la medida y la proporción, una superficie sobre la cuál el color las hará tan presentes como tangibles. Aunque parece que sus significados se encierran en sí mismos y lo que podemos traducir es un modo de equivalencia posible en Mallarmé, una aproximación a modo de respuesta proposicional a la forma en LeWitt, cabe también enlazar todo ello con el secreto fondo verdadero de las pinturas murales del Quattrocento.

Desde otra posición bastante contrastada, durante los años 60 Claude LéviStrauss, padre de la antropología estructural, emprende una postura negativa contra el arte abstracto. Señala como defecto que el atributo esencial de la obra de arte es aportar una realidad de orden semántico. En este sentido, líneas y colores serían elementos que por ellos mismos no poseerían ninguna significación, pero sí serían los medios que permitirían expresar la significación de los objetos. En otras palabras, para reformular esta posición en términos de signos lingüísticos, las líneas y los colores serían puros significantes sin significados. Sobre esta tesis emitiría el veredicto Lévi-Strauss para condenar el arte abstracto, y más ampliamente el arte contemporáneo. Siguiendo su criterio, si no hubiese ninguna relación obvia entre la obra y el objeto que la ha motivado, no estaríamos ante una obra de arte, sino más bien ante un objeto de orden lingüístico. Una vez reducida a objeto lingüístico perdería toda la fuerza, a la vez que toda su capacidad de significar, de emocionar, de manera que no podríamos calificarla como obra de arte. Pero curiosamente, si Lévi-Strauss confirma que el signo lingüístico es autónomo en relación al objeto, dicha autonomía sería un despropósito para la obra de arte. ¿Por qué lo plantea de esta manera?

El academicismo del significado valida los objetos representados a través de una convención y de una tradición. El academicismo del significado, característico de las tentativas de los pintores abstractos donde cada uno intenta analizar su propio sistema, disolverlo, agotarlo totalmente y vaciarlo entonces de su función significativa, retirándole incluso la posibilidad de significar. (Strauss citado en Roque, 2003, p. 294).

La postura del más abstracto de los antropólogos siempre ha suscitado 
sorpresa en los artistas abstractos postestructuralistas, al descubrir qué arte es el que interesaba a Lévi-Strauss: un arte narrativo vinculado a corrientes figurativas del realismo fantástico, como se desvela en las entrevistas de Charbonnier (2005).

Entre estos parámetros se configura la diversidad de la tendencia hacia la síntesis: las formas y colores reemplazan el significado, es decir, el sujeto de la abstracción. Vemos como la relación del lenguaje con el arte abstracto se despliega continuamente en múltiples direcciones. Un hecho es considerar que las obras abstractas esten constituidas por signos y otra, examinar hasta qué punto el lenguaje verbal ha servido de modelo para pensar el arte abstracto. Sin embargo, esta cuestión es al igual que las líneas paralelas que discurren juntas pero discrepan en lo verbal o en lo visual.

\section{Conclusión}

La abstracción puede así aparecerse bajo el aspecto de un organismo hermético y un hecho lingüístico que no admite versiones ajenas a su orden estructural poético o formal. Podría decirse que se trata de una inflexible operación compositiva de un músico matemático.

La reflexión de LeWitt nos devuelve al objeto de inicio de este artículo y verifica como la descripción lingüística se acerca a una explicación sobre el arte abstracto:

El dibujante y la pared entablan un diálogo. El dibujante se aburre pero más adelante a través de esta actividad sin sentido encuentra paz o aflicción. Las líneas sobre la pared son el residuo de este proceso. Cada línea es igual de importante que las otras. Todas las líneas pasan a ser una sola cosa. El espectador de las líneas no ve nada más que las líneas sobre la pared. No tienen sentido. Esto es arte. (LeWitt, 1970).

Aún siendo así, la representación de esta futilidad de las líneas acoge tanto la univocidad del arte como una percepción de la libertad en su sentido más primordial. La lejanía cronológica entre los sujetos expuestos: Piero, Mallarmé y LeWitt no resulta fácilmente inteligible, no obstante durante el recorrido sugerido se hace patente cómo persiguen una forma de gramática organizativa, por pensar en tres prototipos de lenguaje en el arte regidos desde la premisa que todos sus elementos mantienen entre sí relaciones sistemáticas. Cabe 
mencionar que muestran una disposición mental estructurada ininterrumpida versus la indagación en el lenguaje plástico proclive a la abstracción geométrica.

En De quinque corporibus regularibus, Piero della Francesca no relacionó los cuerpos geométricos con determinados elementos sino que se limitó a estudiar las características matemático-geométricas de sus formas. El escrito destaca porque los cinco cuerpos regulares de la geometría: tetraedro, cubo, octaedro, dodecaedro e icosaedro se pueden incluir dentro de una esfera y porque no pueden simplificarse más. Los lados de estas figuras están formados por polígonos regulares. Los cubos, poliedros o bucles de Sol LeWitt ponen de relieve un interés compartido por su antecesor en la matemática que proyecta el espacio. En la escena pictórica desempeña un papel relevante desde el punto de vista formal: la aritmética y las mediciones eran dos conceptos de singular importancia. Al no exisitir ninguna unidad de medida unitaria, ni moneda, ni pesos ni tamaños constituyeron una necesidad. El contenido de cualquier recipiente debía calcularse por sí mismo, de manera que la capacidad de cálculo tenía que ejercitarse continuamente. Se recurría para ello a dividir imaginariamente los objetos en cilindros, círculos y otras formas geométricas similares. Se entiende así que los artistas recurriesen a un repertorio compositivo estandarizado, ya que determinadas formas permitían al espectador poco ejercitado en las matemáticas captar el espacio.

La pintura equivalía a una leyenda sin palabras, ilustrativa de un mensaje. Dicha categoría narrativa no se hará presente en LeWitt, pero paulatinamente la instalación de sus murales en lugares vividos, pintados anteriormente, con un valor de escala humana completamente opuesto a la geografía americana conformarán su manera de abarcar el espacio. Perseguirá una experiencia similar a la de sus antecesores y conseguirá autocontemplarse en esa dimensión. La naturaleza del muro, el significado del fresco en la tradición renacentista, la luz y su color, se transforman en más que factores de atracción para Sol LeWitt: intervienen en su percepción modificando la manera de entender sus propias convenciones. Si tradicionalmente en el Renacimiento temprano el color se utilizaba para la construcción geométrica y para crear efectos de profundidad, a través de las relaciones estipuladas entre los diferentes valores cromáticos se podía determinar la situación de un cuerpo o de una superficie. LeWitt siguiendo su premisa que "la percepción de ideas conduce a nuevas ideas" aporta con su criterio una predisposición a imaginar otros resultados para aspectos colorísticos donde dibujo y color se conciben continuos.

Si para Mallarmé la certidumbre del hallazgo de una nueva dimensión poética, significa la apertura hacia el espacio contemporáneo, la poesía como lenguaje puro y directo puede reflejarse en la síntesis que proyecta la geometría. 
El germen de la página es el contenedor de la posibilidad, del impulso estimulante, de la multiplicidad de perspectivas poéticas en su sentido más universal. La página de LeWitt enlaza su discurso en una extensión constelada de formas y colores profundamente analizado en su recorrido serial.

El wall drawing Whirls and Twirls 1 de la Sala de Lectura Panizzi funciona como catalizador, como un haz de posibles significaciones que induce al lector a la libertad interpretativa. El deseo de integración en el caso del muro como soporte que registrará eventualmente su obra de manera perecedera, lleva a Sol LeWitt a eliminar intermediarios y a elegir dibujar directamente sobre éste para acercarse a la bidimensionalidad del espacio circundante. Cuando las intervenciones se realizan en paredes alzadas en territorio italiano es inevitable que la emulación de sus antecesores, adscritos a su memoria pictórica adquirida en sus estancias en Italia, no trasluzca. Su bagaje se hace presente, como su disfrute por la neutralidad que caracteriza los espacios públicos seleccionados, siendo cómplice al capturar nuevamente al observador. La pared y la página se confirman como el "espacio absoluto" donde compartir su experiencia con el espectador.

\section{Referencias}

Bochner, M. (1996). Arte en serie. En Minimal Art (pp. 83-87). Donostia, Koldo Mitxelena Kulturenea. Diputación Foral de Guipuzkoa.

Charbonnier, G. \& Lévi-Strauss, C. (2005). Entrevistas con Claude LéviStrauss. Madrid, Amorrortu Editores España SL.

Deleuze, G. (2002). Diferencia y repetición. Buenos Aires, Amorrurtu editores.

García, A., LeWitt, S., Miller-Keller, A. \& Rose, B. (1996). Sol LeWitt.

Dibujos murales. Wall Drawings. Madrid, Sala de las Alhajas. Caja de Madrid.

Jakobson, R. (1973). Essais de linguistique générale 2. Rapports internes et externes du langage. Paris, Éditions du Minuit.

Judd, D. (1991). Écrits 1963-1990. Paris, Daniel Lelong éditeur.

Krauss, R. E. (1996). La originalidad de la vanguardia y otros mitos modernos. Madrid, Alianza Forma. Alianza editorial, S.A.

Laskowski, B. (2000). Piero della Francesca. Köln, Könemann Verlagsgesellschaft. 
LeWitt, S. (1970, abril 6). El dibujante y la pared. En "Wall Drawings", Arts Magazine, 44. New York.

LeWitt, S. \& Miller-Keller, A. (1994). Sol LeWitt Critical Texts. Roma, I libri di AEIOU.

Mallarmé, S. (2002). Fragmentos sobre el libro. Murcia, Colección de Arqui-lectura $n^{\circ} 39$. Colegio de Aparejadores y Arquitectos técnicos de la región de Murcia.

Montolío, C. (1996, marzo). Sol LeWitt, la lógica de la brevedad y el orden de lo efímero. Una especial forma de pintar las paredes con fórmulas de matemática belleza. Revista Internacional de Arte LÁPIZ 120. Año XV.

Publicaciones de Estética y Pensamiento, S.L. 48-55.

Roque, Georges (2003). Qu'est-ce que l'art abstrait? Une histoire de

l'abstraction en peinture (1860-1960). Paris, Éditions Gallimard.

Collection Folio Essais.

Wollheim, R. (1996). Minimal Art. En Minimal Art (pp. 23-31). Donostia, Koldo Mitxelena Kulturenea. Diputación Foral de Guipuzkoa. Zeller, H. R.(1980/1978). Mallarmé and Serialist Thought. En Sol LeWitt. New York, The Museum of Modern Art.

Eugènia Agustí: Doctora y profesora del departamento de Pintura de la Universidad de Barcelona.

Contact Address: Facultad de Bellas Artes. Universidad de Barcelona. Departamento de Pintura. c/ Pau Gargallo 4, 08028 Barcelona (España). E-mail address: euagusti@ub.edu 